\title{
The Influence of co-catalyst in the Polymerization of 1,3-butadiene Catalyzed by Neodymium Chloride Tripentanolate
}

\author{
Luis Alexandro Valencia López, ${ }^{1}$ Francisco Javier Enríquez-Medrano, ${ }^{2}$ Hortensia Maldonado Textle, ${ }^{2}$ \\ Florentino Soriano Corral, ${ }^{2}$ Héctor Ricardo López González, ${ }^{2}$ Claude St Thomas, ${ }^{2}$ Francisco Hernández \\ Gámez, ${ }^{2}$ José Luis Olivares Romero ${ }^{3}$ and Ramón Enrique Díaz de León Gómez ${ }^{2 *}$ \\ 1 University of Freiburg, Stefan-Meier-Strasse 31, 79104, Freiburg im Breisgau, Germany \\ 2 Centro de Investigación en Química Aplicada, Blvd. Enrique Reyna, No. 140, 25294, Saltillo, Coahuila, México \\ 3 Instituto de Ecología A.C., Red de Estudios Moleculares Avanzados Campus III, Carretera Antigua a Coatepec, No. 351, \\ 91070, Xalapa, Veracruz, México \\ * ramon.diazdeleon@ciqa.edu.mx
}

Received March $3^{\text {rd }}, 2016$; Accepted July 6 ${ }^{\text {th }}, 2016$.

\begin{abstract}
Triisobutylaluminum (TIBA), triethylaluminum (TEA), diisobutylaluminum hydride (DIBAH) and methylaluminoxane (MAO) were evaluated as activators of neodymium chloride tripentanolate catalyst in order to investigate their influence over the catalytic activity, macro- and microstructure, and thermal properties of of resulting polybutadienes. The higher catalytic activities were achieved by TEA and TIBA as co-catalysts, whereas TIBA and DIBAH led to the polymers with highest cis-1,4 structure content with 98.4 and $97.3 \%$ respectively. The catalytic activity was remarkably poor with MAO as co-catalyst, as well as low stereocontrol. Number average molecular weight values were observed in the range of 260 to $720 \mathrm{~kg} / \mathrm{mol}$.

Key words: Coordination polymerization; catalyst system; neodymium; aluminum co-catalyst; 1,3-butadiene.
\end{abstract}

\section{Introduction}

Polybutadiene (PB) has been an important focus of research effort during the last half-century due to its vast field of applications arising from its low temperature resistance, as well as the allylic hydrogen atom and the weakly double bonds which provide the possibility of grafting and crosslinking, in addition to its easy tunable properties which can significantly vary according to the micro- and macrostructure. According to the employed catalyst system different types of PB can be obtained; being high cis-PB ( $\geq 92 \%$ cis-1,4 content) produced by means of coordination polymerization using different metal catalysts such as titanium, cobalt, nickel and Neodymium (Nd) [1-4], each of which generate polymers that vary considerably in terms of macrostructure, which is mainly dependent on the metal catalyst's ability to undergo chain-transfer reactions. In this matter, early transition metals such as titanium based catalysts are less likely to participate in beta-hydride chain transfer reactions than the more electron-rich late transition metals, allowing the formation of polymers with narrow molar mass distributions index and branching degree. Late transition metals
Resumen. Triisobutilaluminio (TIBA), trietilaluminio (TEA), hidruro de diisobutilaluminio y metil aluminoxano (MAO) fueron evaluados como activadores del catalizador tricloruro de neodimio tripentanolato en la polimerización de 1,3-butadieno. Se determinó la influencia de los sistemas catalíticos sobre la actividad catalítica, microestructura, macro-estructura y propiedades térmicas de los polímeros resultantes. La mayor actividad catalítica fue observada cuando TEA y TIBA fueron empleados. Por su parte, TIBA y DIBAH dieron lugar a la obtención de polibutadienos con el mayor contenido de microestructura cis-1,4, con 98.4 y $97.3 \%$ respectivamente. La actividad catalítica fue marcadamente pobre al utilizar MAO quién condujo además a un bajo estereocontrol. Los pesos moleculares promedio en número fueron observados en el rango de 260 a $720 \mathrm{~kg} / \mathrm{mol}$.

Palabras clave: Polimerización por coordinación; sistema catalítico; neodimio; co-catalizador de aluminio; 1,3-butadieno.

on the other hand such as nickel and cobalt systems are dominated by metal hydride chain transfer reactions, thus leading to polybutadienes with very large molar mass distributions, and high branching degree. As far of the Neodymium systems, their macrostructure is mainly controlled by the propensity of the catalyst to chain transfer reaction to the aluminum co-catalyst [5], distinguishing the formed polybutadienes for being linear polymers but with broad molar mass distributions, giving them, together with their very high cis content of around $98 \%$, very special properties such as excellent abrasion and fatigue resistance besides easy processing, which are taken as advantages for specific applications such as in the tire industry where they are blended with polyisoprene and/or SBR and applied in either sidewalls, threads or rims of tires [6].

There has been reported two types of $\mathrm{Nd}$ catalyst systems: ternary systems comprising a $\mathrm{Nd}$ carboxylate, an alkylaluminum and a halogen source, or binary systems constituted by Neodymium halide complexed with three equivalents of a Lewis base such as alcohols or any other electro-donor organic compound and a trilalkylaluminium as co-catalyst [7,8]; the behavior of both types of catalyst systems is rather similar, 
however are the ternary systems which have been more extensively studied, leaving a huge field of research concerning the binary catalyst systems to be developed. Contributing to this field, Zhang et al., 2007 [9] reported the binary catalyst system $\mathrm{NdCl}_{3} \cdot 3 \mathrm{EHOH}$ (2-ethylhexanol)/TEA for isoprene polymerization; finding a higher catalytic activity than the ternary system $\mathrm{NdV} / \mathrm{DEAC} / \mathrm{DIBAH}$ and a cis-1,4 structure content of around $96 \%$ which could be easily tuned by playing with the $\mathrm{Al} / \mathrm{Nd}$ molar ratio. Masuda et al., 2002 [10] on the other hand employed a catalyst system comprised by $\mathrm{Nd}$ isopropoxide $\left(\mathrm{Nd}(\mathrm{O} i-\mathrm{Pr})_{3}\right.$ activated by MAO, yielding a high efficient polymerization with a moderate high cis-1,4 stereospecificity (around $90 \%$ ), which increased to up to $95 \%$ by using chlorinated co-catalysts such as DEAC. Rao et al., in 1999 [11] introduced the catalyst system $\mathrm{Nd}$ tripentanolate $(\mathrm{NdCl} 3 \cdot 3 \mathrm{~L}$, where $\mathrm{L}=1$-, 2- or 3-pentanol) using TEA as co-catalyst, which allowed the generation of polymers with $99 \%$ of $c i s-1,4$ structure. Furthermore it was found that this catalyst allowed also a proper tuning of the micro- and macrostructure by varying the ratio of the catalyst and co-catalyst, and lead to catalytic activities higher than even many of the ternary Nd based catalyst systems. Taking this as reference, and considering the significant role of the type of co-catalyst due to the type of termination that Neodymium-based catalysts undertake, our group has intended to investigate further this catalyst system, looking forward to get a better understanding about the behavior of this catalyst system, and find the optimal reaction conditions. Recently we studied also the polymerization of butadiene by means of $\mathrm{NdCl}_{3}$ tripentanolate and TIBA as co-catalyst, focusing on studying the effect of the catalyst aging time and the reaction temperature [12]. In this research work it was evaluated different co-catalysts (TIBA, TEA, DIBAH and MAO) investigating in detail the role of them played over the catalytic activity, microand macrostructure, as well as the thermal properties of the resulting polymers.

According to the current knowledge, the proposed mechanism of formation of active sites is comprised by firstly an alkylation reaction followed by the complexation between the Neodymium compound and an organoaluminum, as represented in Fig. 1.

In addition, it is noteworthy the variety of products which might be formed in this complexation step, resulting in different active sites which vary not only in structure, but also in kinetic behavior. The proposed structure of the possible active sites reported in the literature is as shown in Fig. 2 [13].

\section{Results and Discussions}

A series of experiments related to the synthesis of polybutadiene catalyzed by neodymium chloride tripentanolate (hereafter called catalyst) and the different co-catalysts in cyclohexane at fixed $\mathrm{Al} / \mathrm{Nd}$ molar ratio of 35 , aging time of 15 minutes at $30^{\circ} \mathrm{C}$ and a polymerization temperature of $50^{\circ} \mathrm{C}$ are shown in Table 1.

Important differences were found in the polymerization behavior among the co-catalysts, in the way that by far the highest catalytic activity was exhibited by using TEA, with which $80 \%$ of monomer conversion was already observed after only 8 minutes; followed by TIBA which after 20 minutes reached $82 \%$ of monomer conversion. With DIBAH on the other hand, $62 \%$ of monomer conversion was observed after 60 minutes, and lastly MAO generated the lowest catalytic activity and only $3 \%$ of monomer conversion after 60 minutes of reaction. These differences between the catalytic activities imply a significant difference in availability of active centers able to initiate the polymerization, which seems to be governed by the different alkylating capacity of the organoaluminum species [14]. The very low catalytic activity observed with MAO as co-catalyst could be attributed to a possible coordination of the alcohol ligand to MAO which led to destabilization of the active site, as it has been reported before for other catalyst systems activated also by MAO $[15,16]$. It is also noteworthy that the trend of catalytic activity behaved inversely proportional

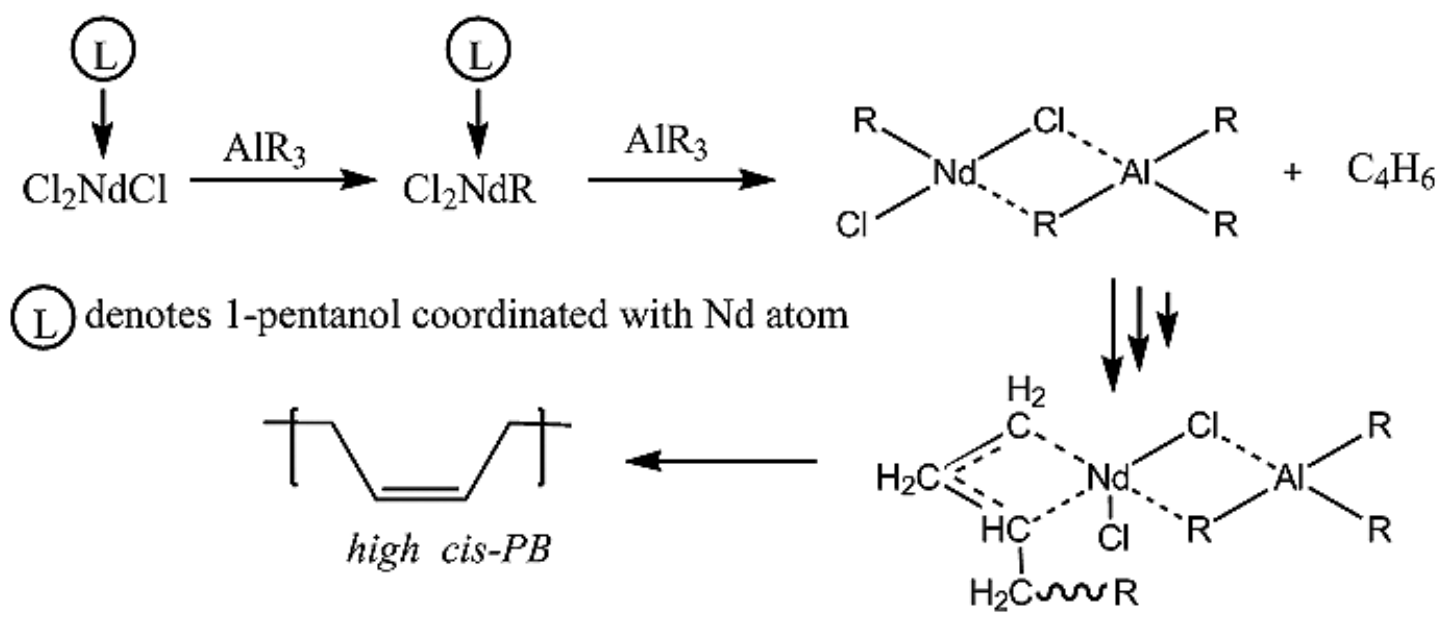

Fig. 1. Mechanism of the active center formation and synthesis of high cis-1,4 $\mathrm{PB}$ by means of $\mathrm{NdCl}_{3} \cdot 3 \mathrm{~L}$ with $\mathrm{L}=1$-pentanol 
<smiles>[R][Cl+][N+]([R])([R])[R]</smiles>

(a)<smiles>[R][Al]1([R])[Cl+][Si]1([R])Cl</smiles>

(c)<smiles></smiles>

(b)<smiles>[R][Al]([R])(Cl)[Al](Cl)Cl</smiles>

(d)

Fig. 2. Catalytic complexes that may are present in the polymerization, (b) and (c) corresponds to active centers according to Manuiko et al. [13]

Table 1. General properties of the resultant polymers.

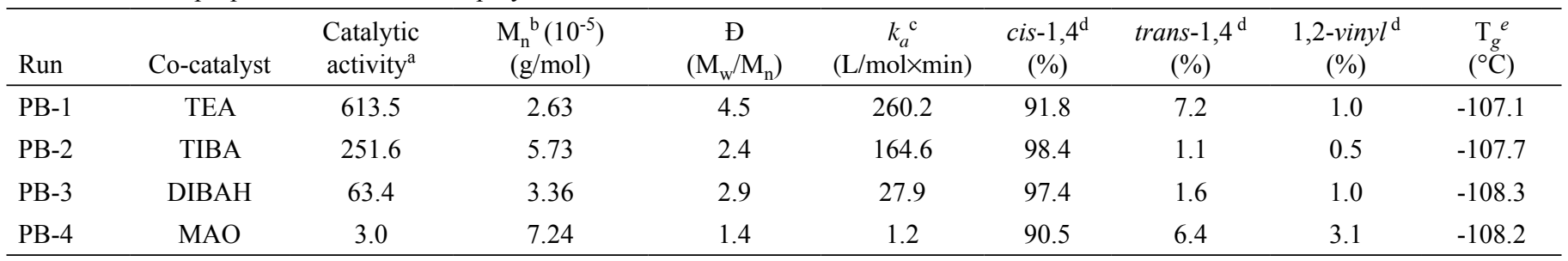

* Note: isothermal polymerizations were performed in cyclohexane at $50^{\circ} \mathrm{C} ;[\text { cyclohexane }]_{0}=8.44 \mathrm{~mol} / \mathrm{L} ;[1,3-\text { butadiene }]_{0}=1.05 \mathrm{~mol} / \mathrm{L}$ $\left[\mathrm{NdCl}_{3} \cdot 3 \mathrm{~L}\right]_{0}=0.547 \mathrm{mmol} ;[\mathrm{Al}] /[\mathrm{Nd}]=35$; aging temperature $=30^{\circ} \mathrm{C}$; aging time $=15 \mathrm{~min}$.

a $\mathrm{kg} \mathrm{PB} / \mathrm{mol} \mathrm{Nd}$ h.

b Determined by size exclusion chromatography (SEC) with polystyrene standards.

c The apparent first order rate constant $k_{a}$ was calculated considering the kinetic law $-\mathrm{d}[\mathrm{M}] / d t=k_{a}[\mathrm{Nd}][\mathrm{M}]$ and from plots $\ln (1-\mathrm{x})^{-1}=f(t)$, where $\mathrm{x}$ is the monomer conversion.

d The microstructures were determinate by ${ }^{1} \mathrm{H}$ and ${ }^{13} \mathrm{C}$ NMR spectroscopy.

e Determined by differential scanning calorimetry (DSC).

to the bulkiness of the substituents in the co-catalyst, being TEA which led to the highest catalytic activity, substituted by simple ethyl groups. This implies that the steric hindrance and electron-releasing effect of bigger or more polar substituents destabilize the catalytic complex. The Fig. 3 shows the plots of $\ln (1-\mathrm{x})^{-1}$ vs polymerization time for different co-catalyst and can be seen in all cases a linear relation, indicating that the polymerization rate can be described by first order kinetics with respect to the monomer concentration, which is in agreement to the reported in the literature for butadiene polymerizations using neodymium based catalysts [17-19], Furthermore it is possible to evaluate the apparent first-order rate constant $\left(k_{\mathrm{a}}\right)$ and the calculated values are summarized in Table 1.

Regarding the molecular weight characteristics summarized in Table 1, it was shown a decreasing tendency by increasing the catalytic activity, since greater amount of available active sites results in a decreased molecular weight of the polymer so formed. On the other hand the decrease in molecular weight was accompanied by an increase in polydispersity index $\left(\mathrm{M}_{\mathrm{w}} / \mathrm{M}_{\mathrm{n}}\right)$ showing that the termination was governed by transfer reactions, being to the organoaluminum compound the characteristic in $\mathrm{Nd}$ based systems, leading to linear polymers but with broad molecular weight distributions. This behavior was found to be intensified significantly by employing TEA as co-catalyst.

The deconvolution of the molar mass distributions, showed in Fig. 4, were carried out in order to give an approximate notion of the amount of types of active sites, elucidating the multimodal behavior of the employed catalysts, which exhibited the different types of active sites showed previously in Fig. 2, and which possess different probabilities of chain transfer and termination processes; therefore producing polymers with individual molar mass distribution and stereo-regularity, being the observed molar mass distributions (see Fig. 4) a superposition of all the normal distributions.

The microstructure of the polybutadienes on the other hand, standing by the disposition of double bonds along the polymer chain, was calculated by means of NMR and the values are shown in Table 1. In general the 1,4 structures content remained high (total cis + trans $\approx 98 \%$ ) in all cases, so they are all in concordance to the mechanism of the bidentate coordination of the monomer, followed by the formation of an anti-allyl unit in the propagating polymer chain end, suggested by Friebe et al., [19]. TIBA and DIBAH prompted the highest cis-1,4 stereoregularity with 98.4 and $97.4 \%$ respectively; followed by TEA $(91.8 \%)$ and lastly MAO which led to $90.5 \%$ cis-1,4 units. 

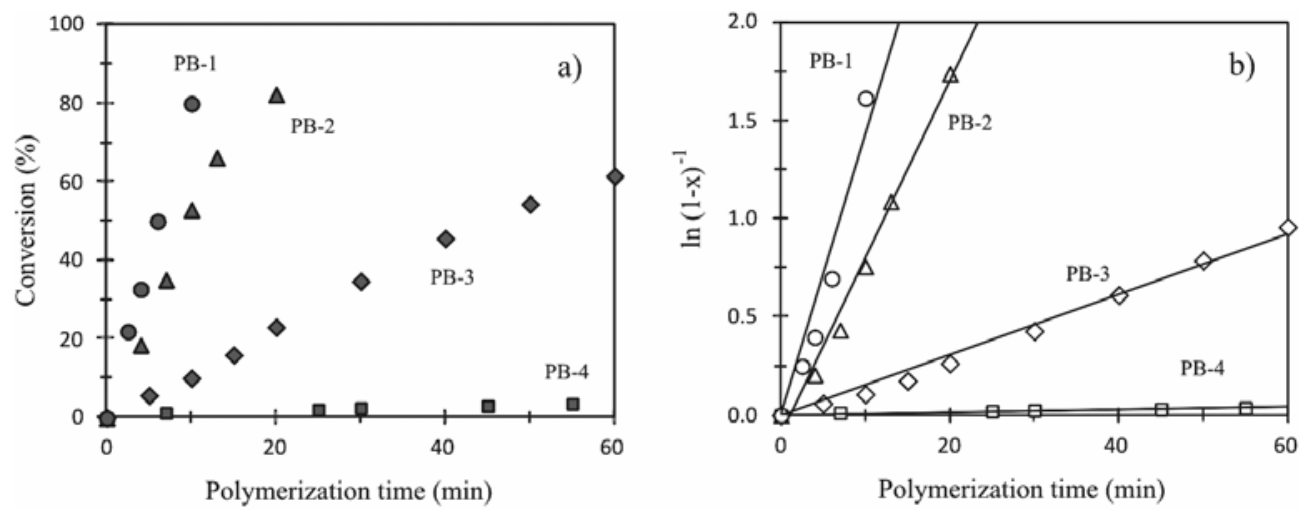

Fig. 3. Monomer conversion and $\ln (1-\mathrm{x})^{-1}$ as a function of polymerization time.

The 1,2-vinyl content remained very low in the case of all alkylaluminums as co-catalysts $(<1 \%)$, as expected, which indicates that the internal $\sigma$-allyl-metal bond is significantly unfavorable compared to the external $\sigma$-allyl-metal bond, which might be formed faster and more often than the internal $\sigma$-allyl bond $[19,20]$. However the 1,2-vinyl content increased to $3.1 \%$ in the case of MAO as co-catalyst. This poor stereocontrol achieved with MAO, might be explained by the low propagation rate, reflected in the low \% monomer conversion in function of time (see Fig. 3), and intensification of anti-sin isomerization role; since the initially formed anti allyl unit would lead exclusively to a cis-1,4 polymer if the rate of the propagation step with incoming monomers is faster than the rate of anti (cis) to syn (trans) isomerization. Furthermore, as it was mentioned before a possible coordination of the alcohol ligands to MAO, could have led to destabilize the active centers, decreasing the catalytic activity and definitely decrease the expected stereocontrol, even by occupying the vacancy of the
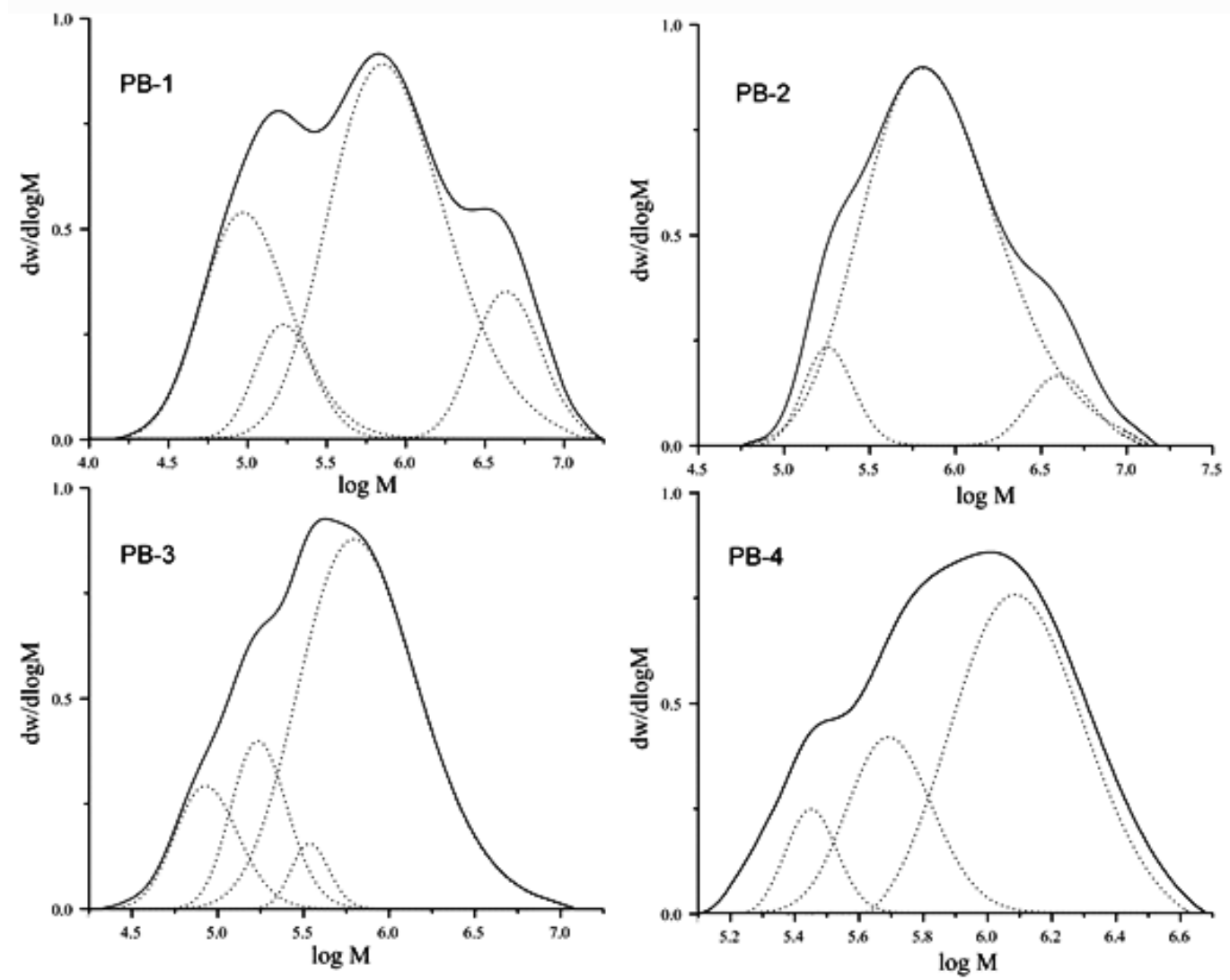

Fig. 4. Deconvoluted molar mass distributions. 
$\mathrm{Nd}$, available to monomer coordination, making the incoming monomer unit to coordinate with only one double bond and increasing the 1,2-vinyl content.

Regarding the thermal properties, it was not observed a significant difference by varying the co-catalyst (see Table 1), remaining the $T g$ values below to $-107.1^{\circ} \mathrm{C}$, which are expected of high cis-1,4 polybutadienes [21].

\section{Experimental}

\section{Reactants}

All manipulations were carried out under inert argon atmosphere in an M-Braun glove box. Cyclohexane purchased from Aldrich was twice distilled from sodium under argon flow before use, and it was handled under inert atmosphere and stored in stainless steel containers. The anhydrous neodymium (III) chloride $\left(\mathrm{NdCl}_{3}\right)(\geq 99.99 \%)$, TIBA $1.0 \mathrm{M}$ in hexane, TEA $1.0 \mathrm{M}$ in hexane, DIBAH 1.0 M in cyclohexane, MAO $10 \mathrm{wt} . \%$ in toluene, isopropanol (99.5\%) and 1-pentanol ( $\geq 99 \%)$ were acquired from Aldrich and they were all used as received. 1,3-butadiene was purchased from Praxair and it was purified by passing it through activated molecular sieve $4 \AA$ and alumina.

\section{Preparation and aging of neodymium-based catalyst}

The catalyst system neodymium chloride tripentanolate of the general formula $\mathrm{NdCl}_{3} \cdot 3 \mathrm{~L}$, where $\mathrm{L}=1$-pentanol was prepared by an alcohol interchange reaction between $\mathrm{NdCl}_{3}$ isopropanolate with 1-pentanol, as reported [10]. Later, in a glass container under inert atmosphere, the freshly prepared neodymium chloride tripentanolate was treated with a $1.0 \mathrm{M}$ of the corresponding aluminum in solution at $\mathrm{Al} / \mathrm{Nd}$ molar ratio of 35 . The resultant mixture was stirred at $30^{\circ} \mathrm{C}$ for 15 minutes (aging step) prior the polymerization.

\section{Polymerization procedure}

Isothermal polymerizations were carried out in a $1 \mathrm{~L}$ stainless steel Parr reactor equipped with a turbine-type mechanical stirrer. The polymerization temperature was controlled by means of an electrical resistance and flow of cold water through an internal tubing coil operated by means of a PDI controller. The cyclohexane was introduced first and then1,3-butadiene monomer was added into the reactor through a $50 \mathrm{~mL}$ stainless steel container. After the monomer addition, the reactor was heated up to $50^{\circ} \mathrm{C}$ and the aged catalytic solution was fed into the reactor through a syringe, and setting-up the stirring at $100 \mathrm{rpm}$.
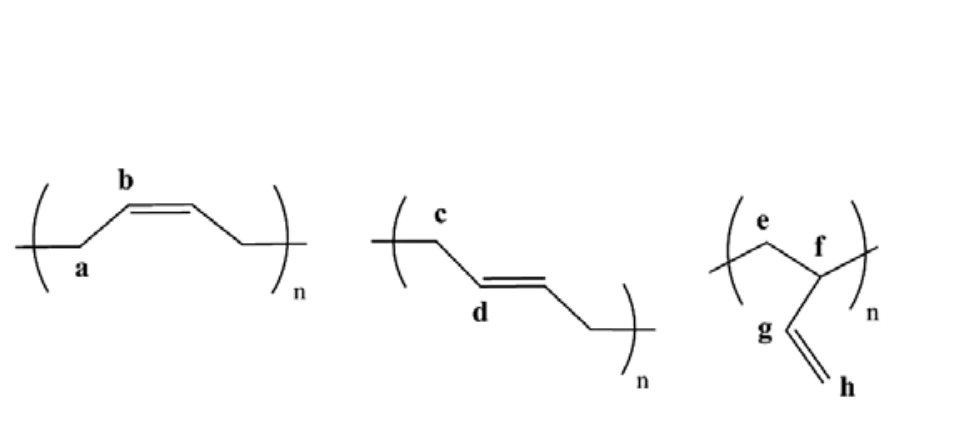

$\mathbf{a}+\mathbf{c}$

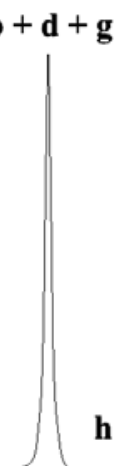

$\mathbf{e}+\mathbf{f}$

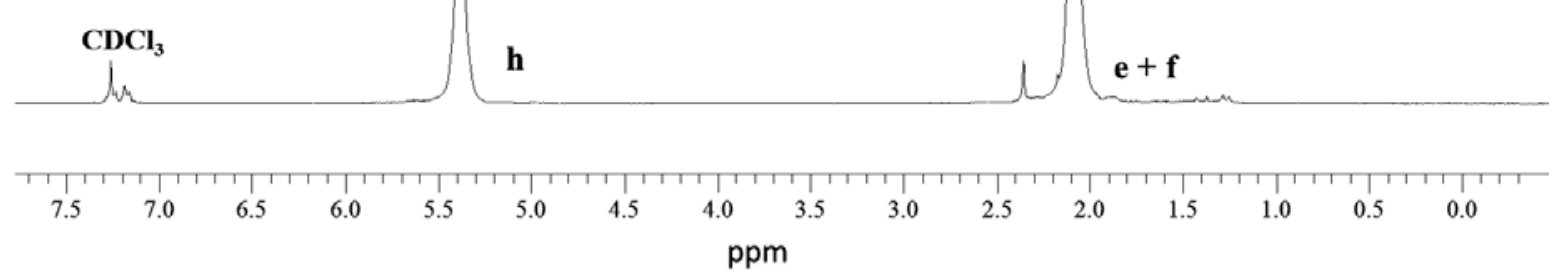

Fig. 5. ${ }^{1} \mathrm{H}$ NMR spectrum of PB-2 (TIBA as activator). 


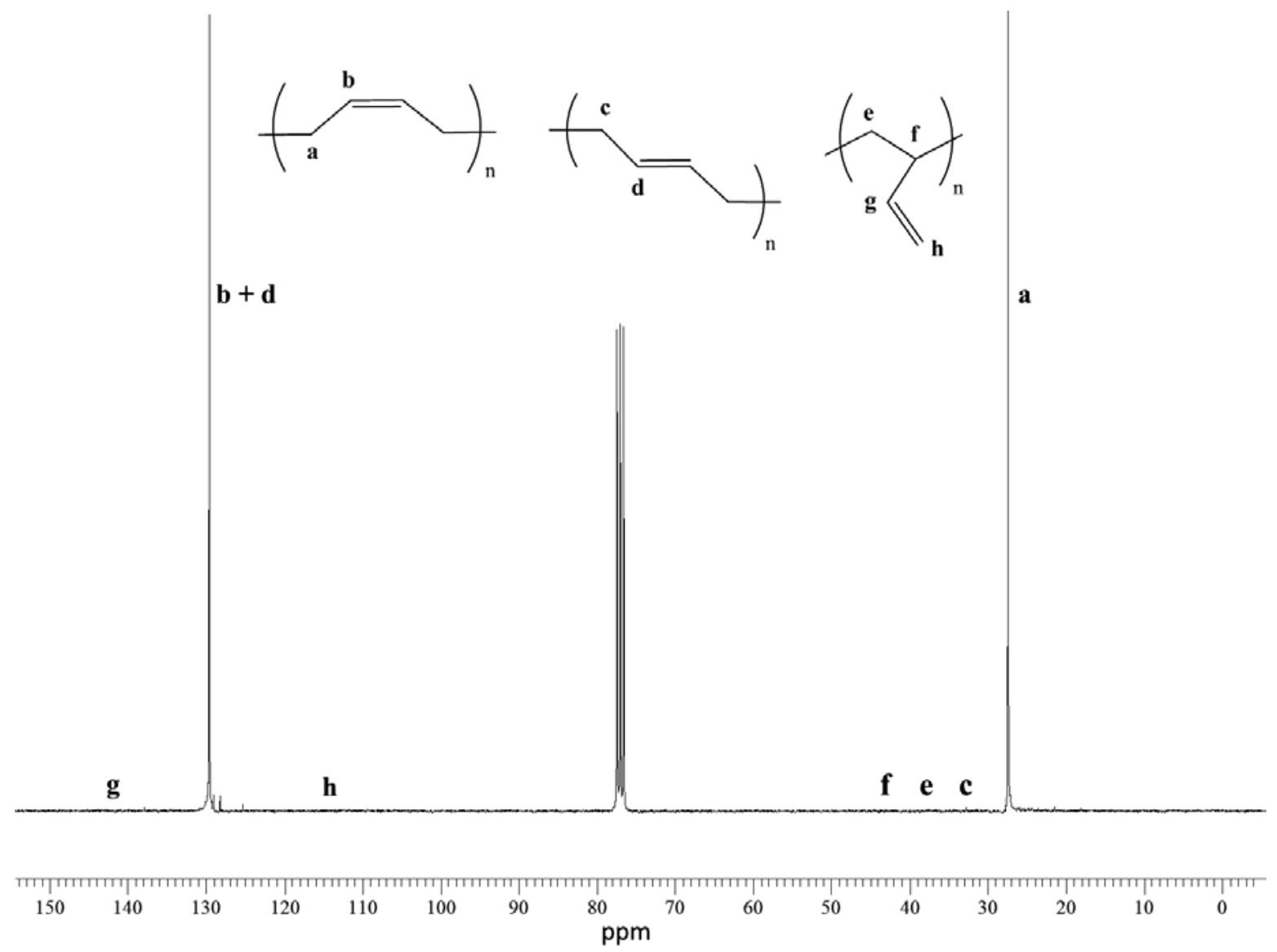

Fig. 6. ${ }^{13} \mathrm{C}$ NMR spectrum of PB-2 (TIBA as activator).

The polymerizations were terminated by adding acidified methanol through a syringe, for later being precipitated in methanol, filtered and dried under vacuum at room temperature until constant weight. Irganox 1076 was added as stabilizer.

\section{Characterization}

The molecular weights of the resulting polymers were calculated by size exclusion chromatography (SEC) using a GPC Alliance 2690 from Waters, equipped with refractive index and viscometer detectors. Calibration was carried out with polystyrene standards and THF as eluent. The deconvolution of the molar mass distributions were carried out by means of the informatics software "peakfit". The microstructure was determined by means of nuclear magnetic resonance (NMR) using a JEOL Eclipse-300 MHz spectrometer with deuterated chloroform as solvent and at room temperature. 1,2-vinyl isomer content in relation with 1,4- (cis + trans isomers) was calculated by ${ }^{1} \mathrm{H} N M R$, integrating the area of olefinic protons located in the chemical shift range from 4.8 to $5.7 \mathrm{ppm}$. The cis/trans ratio was calculated by ${ }^{13} \mathrm{C}$ NMR (proton gated decoupling no-NOE experiments) integrating the area of aliphatic carbons located in the range from 27 to $33 \mathrm{ppm}$. Figures 5 and 6 show the ${ }^{1} \mathrm{H}$ and ${ }^{13} \mathrm{C}$ NMR spectra respectively corresponding to $\mathrm{PB}-2$, in order to illustrate the assignment of signals. Differential scanning calorimeter (DSC) was performed by means of a TA instruments DSC 2920 at a heating rate of $10{ }^{\circ} \mathrm{C} / \mathrm{min}$ and under inert atmosphere.

\section{Conclusions}

The polymerization of 1,3-butadiene by means of $\mathrm{NdCl}_{3}$ tripentanolate activated by TIBA, DIBAH, TEA and MAO was carried out. In general, all systems led to high cis-1,4 polybutadienes with multimodal molar mass distributions, characteristic of $\mathrm{Nd}$ based catalyst due to the multisite nature and chain transfer reactions to the co-catalyst.

Comparing the polymers formed with each activator, TEA was found to generate the highest polymerization activity but a rather low stereospecificty with $91.8 \%$ of $c i s-1,4$ structure; and a relatively narrow molar mass distribution. TIBA on the other hand led to the highest cis-1,4 structure with $98.4 \%$, as well as the narrowest molar mass distribution. DIBAH led to $97.4 \%$ of $c i s-1,4$ structure and a relatively narrow molar mass distribution, however the catalytic activity and propagation rate was found to be lower than expected. MAO as co-catalyst on the other hand, let to the lowest polymerization activity and poorest 
stereo-control. By this we demonstrated the influence which each co-catalyst plays over the polymer final properties and which trend this influence follows, which is of sum importance when searching for a polymer with specific properties and applications.

\section{Acknowledgements}

The authors thank to Ricardo Mendoza, Judith Cabello and Jesús Cepeda for their technical support, as well as Juan Uriel Peña Castillo for his support on the bibliographic research.

\section{References}

1. Sivaram, S.; Upadhyay, V. K. J. Macromol. Sci., Part A: Pure and Appl. Chem. 1992, 2009, 29, 13-19.

2. Pires, N. M.; Coutinho, F. M.; Costa, F. A. Eur. Polym. J. 2004, 40, 2599-2603.

3. He, A.; Huang, B.; Jiao, S.; Hu, Y. J. Appl. Polym. Sci. 2003, 89, 1800-1807.

4. Mello, I. L.; Coutinho, F. M.; Nunes, D. S.; Soares, B. G.; Costa, M. A. Eur. Polym. J. 2040, 40, 635-640.

5. Mark, H. Encyclopedia of Polymer Science and Engineering, 3a. ed., Wiley-Interscience: New York, 2003.

6. Roesky, P. W. Molecular catalyst of rare earth elements, 1a. ed., Springer: New York, 2010.

7. Zhiquan, S.; Jun, O.; Fusong, W.; Zhenya, H.; Fusheng, Y.; Baogong, Q.; J. Polym. Sci., Part A: Polym. Chem. 1980, 18, 3345-3357.
8. Rao, G. S.; Upadhyay, V. K.; Jain, R. K. Angew. Makromol. Chem. 1997, 251, 193-205.

9. Ren, C.; Li, G.; Dong, W.; Jiang, L.; Zhang, X.; Wang, F. Polymer 2007, 48, 2470.

10. Dong, W.; Masuda, T. J. Polym. Sci., Part A: Polym. Chem. 2002, 40, 1838.

11. Rao, G. S.; Upadhyay, V. K.; Jain, R. C. J. Appl Polym. Sci. 1999, 71, 595-602.

12. Enríquez-Medrano F. J.; Valencia-López, L. A.; de Santiago-Rodríguez Y.; Soriano-Corral F.; Saade-Caballero H.; López-Quintanilla M. L.; Díaz de León-Gómez R. J. Polym. Eng. 2015, 35, 105-112.

13. Manuiko, G.; Salakhov, I.; Demidova, E.; Theoretical Foundations Of chemical Engineering. 2010, 44, 142-145

14. Wilson, D. J. J. Polym. Sci., Part A: Polym. Chem. 1995, 33, 2505-2513.

15. Hu, Y.; Zhang, C.; Liu, X.; Gao, K.; Cao Y. J. Appl. Polym. Sci. 2014, 131, 40153

16. Hu, Y.; Dong, W.; Masuda, T.; Macromol. Chem. Phys. 2013, 214, 2172-2180.

17. Friebe, L.; Windisch, H.; Nuyken, O.; Obrecht, W. J. Macromol. Sci. Part A: Pure Appl. Chem. 2005, A41, 245-256.

18. Nikaf, J. B.; Burford, R. P.; Chaplin, R. P. J. Polym. Sci., Part A: Polym. Chem. 1995, 33, 1125-1132.

19. Friebe, L.; Nuyken, O.; Windisch, H.; Obrecht. W.; Macromol. Chem. Phys. 2002, 203, 1055-1064.

20. Cheung, M.; Boateng, V. B.; Fellers, J. F.; White, J. L.; J. Appl. Polym. Sci. 1982, 27, 1395-1407.

21. Kwag, G.; Macromolecules 2002, 35, 4875-4879. 